\title{
Selective Ablation of a Class of Amacrine Cells Alters Spatial Processing in the Retina
}

\author{
John R. Sinclair, ${ }^{*}$ Adam L. Jacobs, ${ }^{*}$ and Sheila Nirenberg \\ Department of Neurobiology, University of California at Los Angeles, Los Angeles, California 90095-1763
}

\begin{abstract}
Several recent studies have suggested that the spatial tuning of retinal ganglion cells may be a more complex process than previously thought. The working hypothesis for many years was that the tuning was shaped by operations performed in the first synaptic layer of the retina, but recent work shows that operations in the second synaptic layer, involving amacrine cells, also play a significant role (Cook and McReynolds, 1998; Taylor, 1999; Flores-Herr et al., 2001). Although it is clear that amacrine cells are involved, the precise roles of the different amacrine subtypes in the many aspects of spatial tuning have not yet been established. Here we used a cell class ablation method to remove one subtype, the neuropeptide Y-expressing cells (NPY cells), and tapped into a part of the circuitry that tunes ganglion cells toward large spatial patterns (low spatial frequencies). When the subtype was ablated, ganglion cells tuned toward low spatial frequencies, both ON- and OFF-type cells, lost this preferential tuning. The effect was specific because ablation of another amacrine subtype did not produce it. Further analysis showed that the change in tuning was attributable to a decrease in the receptive field surround size of the ganglion cell. Other parameters, such as the size, strength, and asymmetry of the center and the strength of the surround, were not statistically significantly affected. These results thus show a mechanism for tuning cells to low spatial frequencies; an operation in the second synaptic layer, mediated by NPY cells, extends the surround of the ganglion cell.
\end{abstract}

Key words: mouse retina; transgenic; spatial processing; spatial tuning; surround inhibition; retinal ganglion cell; amacrine cell; neuropeptide $\mathrm{Y}$; GABA

\section{Introduction}

One of the basic functions of retinal ganglion cells is to extract information about spatial patterns (Barlow, 1953; Kuffler, 1953). This extraction occurs on many different scales (Rodieck and Stone, 1965; Enroth-Cugell and Robson, 1966). For example, some cells extract information on a large scale, as would be necessary to pull out a large object from a busy background (e.g., a tree on a grassy hillside). Other cells extract information on a small scale, as would be necessary to pull out fine details (e.g., the branches on the tree).

The mechanisms that underlie this spatial tuning are only partially understood. The process is thought to begin in the first synaptic layer of the retina, where center-surround receptive fields are first generated (Werblin and Dowling, 1969; Naka and Witkovsky, 1972; Thibos and Werblin, 1978). Lateral inhibition, mediated by horizontal cells, modulates the signaling between photoreceptors and bipolar cells. This creates center-surround antagonism at the level of the bipolar cells, which is then passed forward to the ganglion cells (Werblin and Dowling, 1969; Naka

\footnotetext{
Received Aug. 27, 2003; revised Dec. 5, 2003; accepted Dec. 6, 2003.

This work was supported by grants from the Klingenstein Fund and the Whitehall Foundation, National Institutes of Health Grant R01EY12978 (S.N.), and a fellowship from the Bank of America-Giannini Foundation (A.L.J.). We thank Richard Palmiter for the generous gift of transgenic animals and Peter Latham and Gene Fridman for helpful discussion and comments on this manuscript.

* J.R.S. and A.L.J. contributed equally to this work.

Correspondence should be addressed to Sheila Nirenberg, Department of Neurobiology, University of California at Los Angeles, 10833 Le Conte Avenue, Los Angeles, CA 90095-1763. E-mail: sheilan@ucla.edu.

D01:10.1523/JNEUROSCI.3959-03.2004

Copyright $\odot 2004$ Society for Neuroscience $\quad$ 0270-6474/04/241459-09\$15.00/0
}

and Witkovsky, 1972). Evidence to support this comes from findings that injection of hyperpolarizing current into horizontal cells produces surround-like responses in ganglion cells (Naka and Witkovsky, 1972; Mangel, 1991).

More recently, it has been shown that lateral inhibition in the second synaptic layer is also involved in shaping center-surround antagonism (Cook and McReynolds, 1998; Taylor, 1999; FloresHerr et al., 2001). In particular, in salamander, much of the surround of at least one type of ganglion cell is mediated by GABAergic inhibition from spiking amacrine cells (Cook and McReynolds, 1998), and subsequent work in mammals has both supported (Taylor, 1999; Flores-Herr et al., 2001) and extended this finding, showing that amacrine cells provide at least two sources of signals that mediate surrounds (Flores-Herr et al., 2001).

These studies thus provide clear evidence that the second synaptic layer is involved in spatial tuning. However, many key questions remain. In particular, how does a given ganglion cell become tuned to a specific spatial scale? Are there dedicated circuits for tuning some cells to large spatial patterns and some to small ones? Which amacrine subtypes are involved in these processes and how?

One of the reasons these questions have been hard to address is that there are very few tools for dissecting second synaptic layer circuitry. This layer is complex, containing 20-30 different amacrine subtypes, each of which may be performing a different function (Masland, 1988; Vaney, 1990; MacNeil and Masland, 1998; MacNeil et al., 1999). Standard tools for dissecting circuit operations, such as neurotransmitter antagonists, are not specific 
enough to target the different subtypes individually, because many of them use the same neurotransmitters (e.g., GABA). Thus, alternative approaches are needed to take the system apart.

Here we used a selective ablation method to remove one amacrine subtype from the retina of the mouse and test its role in spatial tuning. The subtype chosen was a set of cells distinguished by its expression of a peptide, neuropeptide Y (NPY) (Marshak, 1989; Hutsler and Chalupa, 1994; Sinclair and Nirenberg, 2001; Oh et al., 2002), and suggested to be involved in processing spatial information (Hutsler and Chalupa, 1994). These cells form a nonrandom array across the retina, lie in two layers [the ganglion cell layer (GCL) and inner nuclear layer (INL)], and are likely inhibitory because they show immunoreactivity to GABA transporter 1 (Sinclair and Nirenberg, 2001). Our results show that this amacrine subtype is involved in spatial tuning, specifically in tuning ganglion cells toward large spatial patterns (low spatial frequencies). When it was removed from the circuitry, ganglion cells tuned to low spatial frequencies lost this preference, and the underlying cause was a change in the size of the receptive field surround. These results thus reveal one mechanism for how ganglion cells become tuned to detect low spatial frequencies.

\section{Materials and Methods \\ Animals}

Two groups of animals were used: (1) C57BL/6J mice that express lacZ, the gene for the enzyme $\beta$-galactosidase ( $\beta$-gal), under the regulation of the NPY gene promoter (Erickson et al., 1996); and (2) wild-type C57BL/6J mice. The $\beta$-gal-expressing line was produced through homologous recombination by disrupting one NPY allele and replacing it with lacZ.

\section{Population experiments}

Ablations. The ablations for the population experiments were performed as described for the in vitro ablations by Nirenberg and Meister (1997), except that an eyecup preparation was used rather than the isolated retina. Briefly, animals were placed in the dark overnight before the experiment and then killed with $100 \% \mathrm{CO}_{2}$. The eye was then removed, and, under dim red light (low-pass filter with a $580 \mathrm{~nm}$ cutoff; intensity, 0.64 $\mu \mathrm{W} / \mathrm{cm}^{2}$ or 250 rod-equivalent photons $\left.\cdot \mu \mathrm{m}^{-2} \cdot \mathrm{sec}^{-1}\right)$, the cornea, lens, and vitreous were removed, and small cuts were made into the eyecup to allow it to lie relatively flat. The retina was bathed in an oxygenated Ringer's solution containing a $\beta$-gal substrate [fluorescein-di- $\beta$ D-galactoside (FDG)], and a sensitizing agent [aminoethyl carbazole (AEC) ] at a concentration of $1.5 \mathrm{mg} / \mathrm{ml} \mathrm{FDG}$ and $35 \mu \mathrm{g} / \mathrm{ml} \mathrm{AEC} \mathrm{in} 2.5 \%$ DMSO for $5 \mathrm{~min}$ (Nirenberg and Meister, 1997). It was then illuminated for 5 min using the fluorescein excitation beam of a Leica (Nussloch, Germany) microscope (model DMLB; filter set model E4; excitation filter bandpass, $436 \pm 3.5 \mathrm{~nm}$; intensity, $10 \mathrm{~mW} / \mathrm{cm}^{2}$ or $8.85 \times 10^{7}$ rod-equivalent photons $\cdot \mu \mathrm{m}^{-2} \cdot \mathrm{sec}^{-1}$ ), focusing on the labeled cells using a $10 \times 0.3$ numerical aperture objective. After this treatment, the eyecup was placed in the dark in oxygenated Ringer's solution for $1 \mathrm{hr}$, during the cell death period. The retina was then removed from the eyecup, and a piece $2.5 \times 2.5 \mathrm{~mm}$ was isolated from the central retina and placed on an extracellular multielectrode array in the recording chamber for physiological recording. The retina was light-adapted for $1 \mathrm{hr}$ with a periodic full-field flashing stimulus, with a mean intensity of $1.0 \mu \mathrm{W} /$ $\mathrm{cm}^{2}$ or 8000 rod-equivalent photons $\cdot \mu \mathrm{m}^{-2} \cdot \mathrm{sec}^{-1}$ and a contrast of 0.4 , where contrast was measured as $\left(L_{\max }-L_{\min }\right) /\left(L_{\max }+L_{\min }\right)$, and $L_{\max }$ and $L_{\min }$ are the maximum and minimum intensities, respectively. The intensity and contrast for the adapting stimulus were the same as those for the experimental stimuli (the gratings and flashes; see below). The time from ablation to presentation of gratings and flashes was $2 \mathrm{hr}$.

Note that all animals in the experimental and nontransgenic control groups received the identical treatment, including the light adaptation, stimulation, and ablation treatment. As indicated in Results, the nontransgenic controls did not undergo ablation from this treatment because they do not express the $\beta$-gal gene. The transgenic controls received the same treatment as well, except for the $\beta$-gal substrate; thus, they also did not undergo ablation.

Stimuli. The grating stimulus consisted of a series of drifting sine wave gratings presented at $1 \mathrm{cycle} / \mathrm{sec}$. The series contained eight spatial frequencies, ranging from 0.0014 to 0.177 cycles ${ }^{\circ}$ (increasing by a factor of 2 from lowest to highest), and three directions. Each spatial frequency and direction were presented for 30 cycles, and the 24 combinations of spatial frequency and direction (eight spatial frequencies $\times$ three directions) were randomly interleaved. The series was presented twice, giving a total of 60 cycles of each spatial frequency and direction. The range of spatial frequencies was optimized for mouse retina, following the method of Stone and Pinto (1993). Retinas were also stimulated with full-field flashes. Stimuli were generated with a liquid crystal display panel (Panasonic PT-L104) driven by an Eiki projector (OHP-4100), and all stimuli were white; i.e., the red, green, and blue channels were equally activated (for spectrum, see Nirenberg et al., 2001, their supplementary information). The mean intensity and contrast of the stimuli (both gratings and flashes) were the same as those described for the adapting stimulus above. Note that the stimulus intensity places it in the coneactivating (photopic) regimen, with rods $>90 \%$ saturated (Dodd, 1998), and that the contrast is in the linear regimen for most cells, specifically at the high end (Stone and Pinto, 1993). The stimulus time was just $>25$ min in total: 24 min of gratings and $100 \mathrm{sec}$ of periodic full-field flashes $(0.5 \mathrm{~Hz})$.

Recordings. Recordings were made as described previously (Nirenberg et al., 2001). Briefly, a 64-electrode array was used, and spike trains were acquired using a Plexon Instruments Multichannel Neuronal Acquisition Processor. With this system, spikes were sorted into individual units on line using a time-voltage window discriminator that captures distinct waveforms. Each waveform was designated a unit (a cell). All units were monitored continuously over the course of the experiment; those that did not remain within the parameters of the window discriminator for the duration of the experiment were automatically discarded.

\section{Before-and-after experiments}

As with the population experiments, the animals were placed in the dark overnight and then killed with $\mathrm{CO}_{2}$ and enucleated. A $2.5 \times 2.5 \mathrm{~mm}$ piece from the central retina was placed in the recording chamber, and the retina was then light-adapted and stimulated with the gratings and flashes. Both the light adaptation (for $1 \mathrm{hr}$ ) and the stimulation with the gratings and flashes (for a total of $25 \mathrm{~min}$ ) were the same as for the population experiments. To ablate the NPY cells, the following was done. FDG and AEC were applied to the retina for $10 \mathrm{~min}$. Specifically, the Ringer's solution in the recording chamber was replaced with Ringer's solution containing FDG and AEC using the same concentrations as used above. The retina was then illuminated for $3.5 \mathrm{~min}$ using the fluorescein excitation beam of an Olympus Optical (Tokyo, Japan) inverted microscope (filter set model UMNIB; excitation filter bandpass, $470-490 \mathrm{~nm}$; intensity, $10 \mathrm{~mW} / \mathrm{cm}^{2}$ or $2.15 \times 10^{8}$ rod-equivalent photons $\left.\cdot \mu \mathrm{m}^{-2} \cdot \mathrm{sec}^{-1}\right)$. After the ablation illumination, the retina was left in complete darkness for $1 \mathrm{hr}$, during which 11-cis-retinal $(100 \mu \mathrm{M})$ was applied for $10 \mathrm{~min}$ to aid in regeneration of bleached photopigment. The retina was then light-adapted for $30 \mathrm{~min}$ and stimulated with the gratings and flashes again for $25 \mathrm{~min}$, as before. Mean stimulus intensity after ablation was $9.1 \mu \mathrm{W} / \mathrm{cm}^{2}$ or 73,400 rod-equivalent photons $\cdot \mu \mathrm{m}^{-2} \cdot \mathrm{sec}^{-1}$. The time from ablation to presentation of the gratings and flashes was $1.5 \mathrm{hr}$. All animals in the experimental and control groups received the identical treatment, including light adaptation, ablation treatment, and stimulation. Recordings were performed as described above.

\section{Analysis of receptive field properties}

The spatial structure of the receptive field was evaluated using the responses to drifting sine wave gratings. For each presented spatial frequency and direction, spike times were recorded relative to grating onset. From these, the first harmonic of the response was computed. Denoting the first harmonic as $R(\mathbf{k})$, where $\mathbf{k}=\left(k_{\mathrm{x}}, k_{\mathrm{y}}\right)$ is the two-dimensional spatial frequency, $R(\mathbf{k})$ was computed via the equation:

$$
R(\mathbf{k})=\left|\frac{2 \pi}{\omega} \frac{1}{N_{\mathrm{c}}} \sum_{j} \exp \left[-i \omega t_{j}(\mathbf{k})\right]\right|,
$$




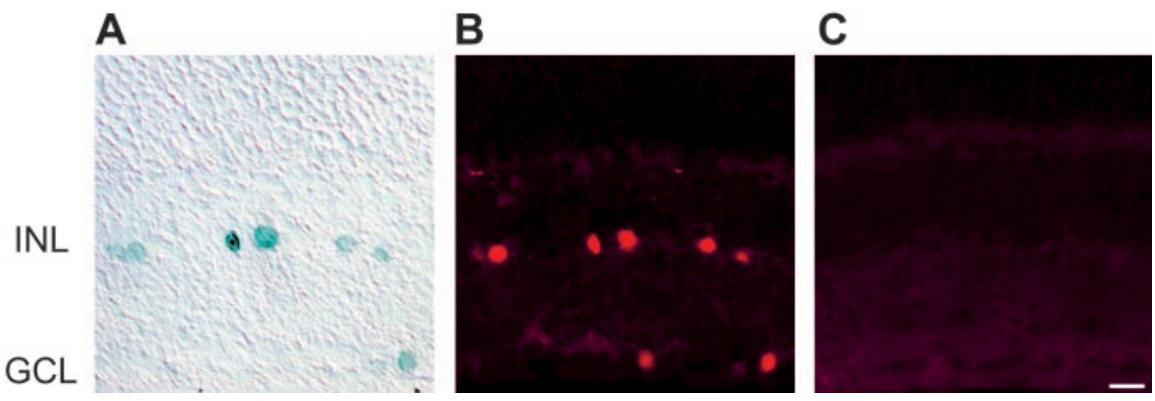

Figure 1. The $\beta$-gal gene is selectively expressed in NPY cells. A, Retinal section from a transgenic mouse that expresses $\beta$-gal under the regulation of the NPY gene promoter. The section was fixed and stained with a histochemical marker for $\beta$-gal, X-gal, which produces a blue product in the $\beta$-gal-expressing cells. B, Same section stained with an antibody to NPY, using a rhodamine red-X fluorescent secondary antibody. C, Control section stained only with the secondary antibody. Scale bar, $20 \mu \mathrm{m}$.

Histochemistry and immunocytochemistry $\beta$-gal activity was detected using 5-bromo-4chloro-3-indolyl-D-galactopyranoside (X-gal) as described by Sinclair and Nirenberg (2001). Immunocytochemistry using SMI32 and NPY antibodies was performed as described by Nirenberg and Cepko (1993) and Sinclair and Nirenberg (2001), respectively. Selectivity for the NPY antibodies was shown by Sinclair and Nirenberg, (2001); retinal sections stained with the antibodies pretreated with excess NPY showed no labeling (Fig. 1B) (Sinclair and Nirenberg).

\section{Results \\ Ablation of NPY cells alters spatial tuning of ganglion cells}

To ablate the NPY cells, we used the method described by Nirenberg and

where $\omega=2 \pi$ radians/sec is the temporal frequency of the drifting grating; $N_{\mathrm{c}}$ is the number of cycles (60 in these experiments); and $t_{\mathrm{j}}(\mathbf{k})$ is the time of the $j$ th spike produced by a grating of spatial frequency $\mathbf{k}$. To determine the parameters of the difference-of-Gaussians model that best fits the responses, $R(\mathbf{k})$, we minimized the mean squared error between $R(\mathbf{k})$ and the response predicted by the model, the latter denoted $\hat{R}(\mathbf{k})$. For this minimization, we followed the standard approach described by Enroth-Cugell et al. (1983), with one addition: the major and minor radii of the center were allowed to be different because we found that many cells had asymmetric centers. $\hat{R}(\mathbf{k})$ was then computed as:

$$
\hat{R}(\mathbf{k})=\left[A_{\mathrm{c}}^{2}(\mathbf{k})+A_{\mathrm{s}}^{2}(\mathbf{k})-2 A_{\mathrm{c}}(\mathbf{k}) A_{\mathrm{s}}(\mathbf{k}) \cos \phi\right]^{1 / 2},
$$

where

$$
A_{\mathrm{c}}=F_{\mathrm{c}} \exp \left[-\frac{1}{2} \sigma_{+}^{2}\left(k_{\mathrm{x}} \cos \theta-k_{\mathrm{y}} \sin \theta\right)^{2}-\frac{1}{2} \sigma_{-}^{2}\left(k_{\mathrm{x}} \sin \theta+k_{\mathrm{y}} \cos \theta\right)^{2}\right]
$$

is the strength of the center response, with $\sigma_{+}$and $\sigma_{-}$the major and minor radii of the asymmetric center, and $\theta$ its orientation:

$$
A_{\mathrm{s}}=F_{\mathrm{s}} \exp \left[-\frac{1}{2} \sigma_{\mathrm{s}}^{2}\left(k_{\mathrm{x}}^{2}+k_{\mathrm{y}}^{2}\right)\right]
$$

is the strength of the surround response with $\sigma_{\mathrm{s}}$ the size of the surround (assumed to be symmetric), and $\phi$ is the phase angle associated with differential delays between center and surround. The mean squared error between $R(\mathbf{k})$ and $\hat{R}(\mathbf{k})$, denoted $\chi^{2}$, is given by:

$$
\chi^{2}=\sum_{\mathbf{k}}(R(\mathbf{k})-\hat{R}(\mathbf{k}))^{2} .
$$

This quantity is minimized with respect to the seven parameters $F_{\mathrm{c}}, F_{\mathrm{s}}$, $\sigma_{+}, \sigma_{-}, \sigma_{s}, \theta$, and $\phi$. Note that $\theta$ depends on the orientation of the retina with respect to the stimulus, which is a function of how the retina is laid down on the electrode array, and is not affected by the ablation. Thus, only six parameters were evaluated for difference attributable to the ablation. In Results and Table 1 , center size, $\sigma_{\mathcal{c}}$, is given, which is the geometric average of major and minor radii of the center, $\sigma_{\mathrm{c}}=$ $\left(\sigma_{+} \sigma_{-}\right)^{1 / 2}$, and center asymmetry, $q$, which is defined as $q=\left(\sigma_{+}-\right.$ $\left.\sigma_{-}\right) /\left(\sigma_{+}+\sigma_{-}\right)$.

Goodness of fit was measured by $r^{2}$, the fraction of the variance explained by the model $r^{2}=\chi^{2} / \operatorname{Var}[R(\mathbf{k})]$. Criteria for inclusion in the data set: $r^{2}>0.6$, and for each parameter, that it was not $>3$ SD from the mean for that parameter. The fraction of cells that passed these criteria was not statistically different between the NPY cell-ablated retinas and controls ( $p>0.9, t$ test; $44 \pm 7 \%$ for NPY cell-ablated retinas and $43 \pm$ $8 \%$ for controls, mean \pm SEM), indicating that the ablation did not affect quality of fit per se but, rather, the parameter values that achieved the fit (i.e., smaller surround size values for the NPY cell-ablated retinas than for the controls).
Cepko (1993). With this method, the targeted cells are first engineered to express the gene for the enzyme $\beta$-gal. They are then labeled with a fluorescent dye by treating them with a fluorogenic $\beta$-gal substrate. Finally, they are killed by light-activating the dye: light activation in the presence of a sensitizing agent produces a lethal reaction in the cells. Previous studies have shown this method to be both effective and selective: $>90 \%$ of targeted cells can be ablated with $<2 \%$ nonspecific cell death, as measured by the selective uptake of a standard cell death marker, ethidium homodimer, into the targeted cells and by the disappearance of the targeted cells from the tissue over time without concomitant loss of neighboring cells (Nirenberg and Cepko, 1993; Nirenberg and Meister, 1997).

To apply the method to the NPY cells in the retina, we did the following. We first obtained a transgenic mouse line from Erickson et al. (1996) that expresses $\beta$-gal under the regulation of the NPY gene promoter. It has been previously shown that $\beta$-gal is correctly targeted in this line because $94 \%$ of $\beta$-gal-positive cells also show NPY immunoreactivity (Sinclair and Nirenberg, 2001) (Fig. 1). We then labeled the cells with the fluorescent dye by superfusing it into the eyecup and then light activated the dye. We evaluated the effectiveness of the ablation by staining the retina with a marker for $\beta$-gal and counting the number of $\beta$-galexpressing cells that remained (Fig. 2).

To test whether the NPY cells play a role in spatial tuning, we compared ganglion cell responses from NPY cell-ablated retinas with those from controls. Two control groups were used: (1) retinas from transgenic animals that received the sensitizing agent and light activation but no $\beta$-gal substrate, so no cells were ablated; and (2) retinas from nontransgenic animals that received the full treatment (the $\beta$-gal substrate, the sensitizing agent, and light activation), but because no cells expressed $\beta$-gal, no cells were ablated. All recordings were made from the central retina.

We evaluated the spatial tuning of the ganglion cells using spatial frequency-tuning curves. Retinas were presented with drifting sine wave gratings of different spatial frequencies, and ganglion cell responses were recorded. A tuning curve was then generated for each cell by Fourier analyzing its responses and plotting the amplitude of the fundamental as a function of the log of the spatial frequency (Enroth-Cugell and Robson, 1966; Stone and Pinto, 1993).

In control retinas, the range of spatial tuning curves was broad: some cells showed maximal power at low spatial frequencies, others at middle spatial frequencies, and still others at high frequencies (Fig. $3 A$, left). In contrast, in NPY cell-ablated reti- 
A

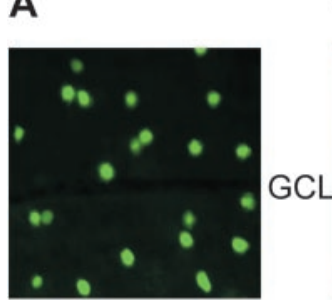

B

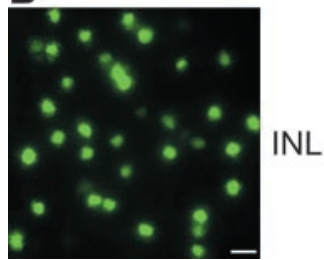

INL
C Ablated

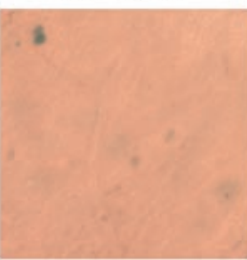

D

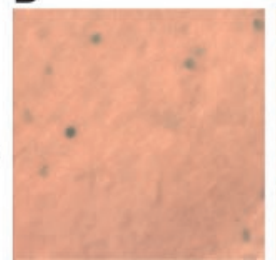

E Control

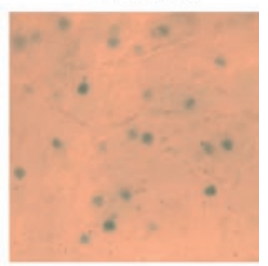

$\mathbf{F}$

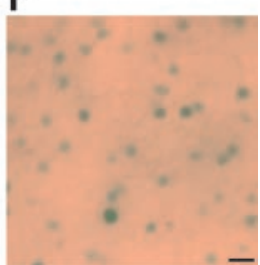

Figure 2. The ablation method is effective on the NPY cells. $A$, Retinal whole mount (live) from a transgenic mouse that expresses $\beta$-gal in the NPY cells. The retina was treated with the fluorogenic $\beta$-gal substrate FDG to label the $\beta$-gal-expressing cells with dye. The plane of focus is on the $\mathrm{GCL}$. $B$, Same retina, with the plane of focus on the INL. $C$, Retinal whole mount after ablation treatment, fixed and stained with the histochemical marker for $\beta$-gal, X-gal, which produces a blue product in the cells. Very few $\beta$-gal-expressing cells remain. The plane of focus is on the GCL.D, Same retina, with the plane of focus on the INL. $E$, Control retinal whole mount, fixed and stained with $X$-gal, for comparison with C. This retina received the sensitizing agent and light activation but no FDG, so no $\beta$-gal-expressing cells were ablated. The plane of focus is on the GCL. F, Same retina, with the plane of focus on the INL. The retinas in $C-F$ were fixed at the end of the recording session, $\sim 4 \mathrm{hr}$ after ablation treatment, and then stained. Scale bar, $20 \mu \mathrm{m}$.

nas, the range was much narrower: most cells showed maximal power in the middle- or high-spatial frequency range (Fig. $3 \mathrm{~A}$, right).

We assessed the power quantitatively by determining, for each ganglion cell, the mean of its tuning curve, that is, its center of mass. This quantity, denoted $C M$, is given by:

$$
C M=\frac{\sum_{\mathrm{k}} R(k) \log k}{\sum_{\mathrm{k}} R(k)},
$$

where $k$ is spatial frequency, and $R(k)$ is the fundamental response at spatial frequency $k$. We then compared the centers of mass for cells from NPY cell-ablated retinas with those from controls. The centers of mass for cells from NPY cell-ablated retinas were significantly higher: by, on average, more than onethird [Fig. $3 B ; p<0.01, t$ test comparing mean center of mass from NPY cell-ablated retinas and controls; mean for NPY cellablated retinas $\pm \mathrm{SEM},-2.04 \pm 0.02 \log$ cycles $/{ }^{\circ} ; n=155$ cells, 10 retinas; mean for controls, $-2.16 \pm 0.03 \log$ cycles $/{ }^{\circ} ; n=219$ cells, 10 retinas ( 7 nontransgenic and 3 transgenic)]. Furthermore, the effect was dose-dependent; that is, retinas with more NPY cells ablated showed a greater shift in center of mass, with the largest shift nearly a factor of 2 (Fig. $3 C$, filled circles; $p<$ 0.002 , linear regression; $n=17$ retinas). Finally, the effect was specific to the NPY cells, because ablation of another population of amacrine cells, the V-cells (Nirenberg and Meister, 1997), did not produce a significant shift (Fig. $3 C$, open circles; $p>0.3$, linear regression; $n=6$ retinas).

These results show that the NPY cells are involved in spatial tuning, specifically, in tuning ganglion cells to low spatial frequencies. To determine how they might mediate their effects, we evaluated the results in the context of ganglion cell receptive fields. Ganglion cell receptive fields are made up of two components, a center and a surround, which are mutually antagonistic
(Barlow, 1953; Kuffler, 1953), and it is the balance between these two that sets the spatial tuning of the cell (Rodieck, 1965; Shapley and Lennie, 1985). Any change in the balance will, therefore, cause a shift in the tuning, and particular changes will produce particular types of shifts. For example, a reduction in the size of the center will cause a shift toward high spatial frequencies, and the shift will appear as an increase in the high-frequency cutoff. A reduction in the size of the surround will also cause a shift toward high spatial frequencies, but this time, the shift will appear as a loss of power at low spatial frequencies.

To determine how the NPY cells affect the center and surround, we fit the spatial tuning curves from NPY cell-ablated retinas and controls to the predictions of a standard receptive field model, a difference-of-Gaussians model (Rodieck, 1965; Enroth-Cugell and Robson, 1966; Enroth-Cugell et al., 1983; Shapley and Lennie, 1985), and examined which parameters of the center and surround were different between the two groups. Six parameters were evaluated: the size of the center and surround, the strength of the center and surround, the asymmetry of the center, and the relative phase between the center and surround. Our analysis showed that the only parameter that was statistically significantly different was the size of the surround. The surrounds for the ganglion cells from the NPY cell-ablated retinas were strikingly smaller, with the distribution showing a clear reduction in the fraction of ganglion cells with large surrounds (Fig. 4, Table $1 ; p<0.05, t$ test comparing mean surround size from NPY cell-ablated retinas and controls; mean surround size \pm SEM for ganglion cells from NPY cell-ablated retinas, $791 \pm 67 \mu \mathrm{m} ; n=77$ cells; from controls, $1065 \pm 77 \mu \mathrm{m} ; n=98$ cells; $p>0.4$ for all other parameters; all $p$ values were Bonferroni-corrected to account for analysis of multiple parameters).

Note that there was no significant difference in the fraction of ganglion cells per retina that showed center-surround fits between the NPY cell-ablated retinas and controls $(p>0.9, t$ test; see Materials and Methods), indicating that the cells with large surrounds were not disappearing, just undergoing a surround size change. Thus, the ablation was effectively converting the cells with large surrounds into cells with small surrounds.

One potential confound is the effect of retinal eccentricity. In several species, receptive field size varies with eccentricity (Wiesel, 1960; Linsenmeier et al., 1982; Croner and Kaplan, 1995; He and Levick, 2000) (for review, see Troy and Shou, 2002). The data are primarily for center size (Cleland et al., 1979; Peichl and Wässle, 1979; He and Levick, 2000), but there is evidence for surround size as well. The dependence of surround size on eccentricity, however, is not clearly consistent across species; e.g., there is a clear but weak dependence in primate (Croner and Kaplan, 1995) but no systematic relationship in cat (Linsenmeier et al., 1982). If there is a surround size dependence on eccentricity in mouse, on the scale of the surround size changes seen with NPY cell ablation, and differences in eccentricity between the NPY cell-ablated retinas and controls were not suitably controlled for, then the interpretation of our results could be confounded.

We addressed this three ways. First, we assessed the extent to which receptive field size depends on eccentricity in mouse. We first examined morphological data. In the largest morphological survey of mouse ganglion cells to date, Sun et al. (2002) reported that there is no observable relationship between ganglion cell dendritic tree size and eccentricity in mouse retina, suggesting that there is little or no relationship between receptive field size and eccentricity in this species. We then assessed this physiologically, specifically by comparing center and surround sizes from 
A

Control

Spatial frequency $-2.9 \quad$ (log cycles/degree) $\quad-0.8$

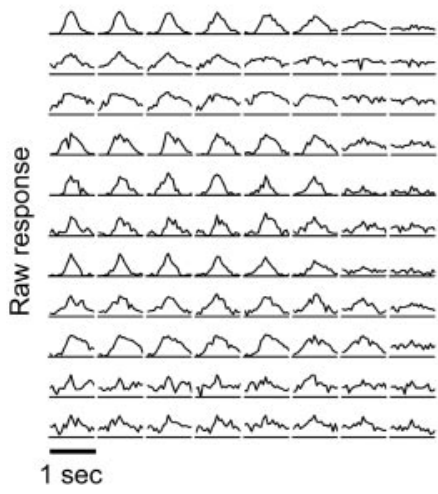

$\left(\log\right.$ cycles $\left./^{\circ}\right)$

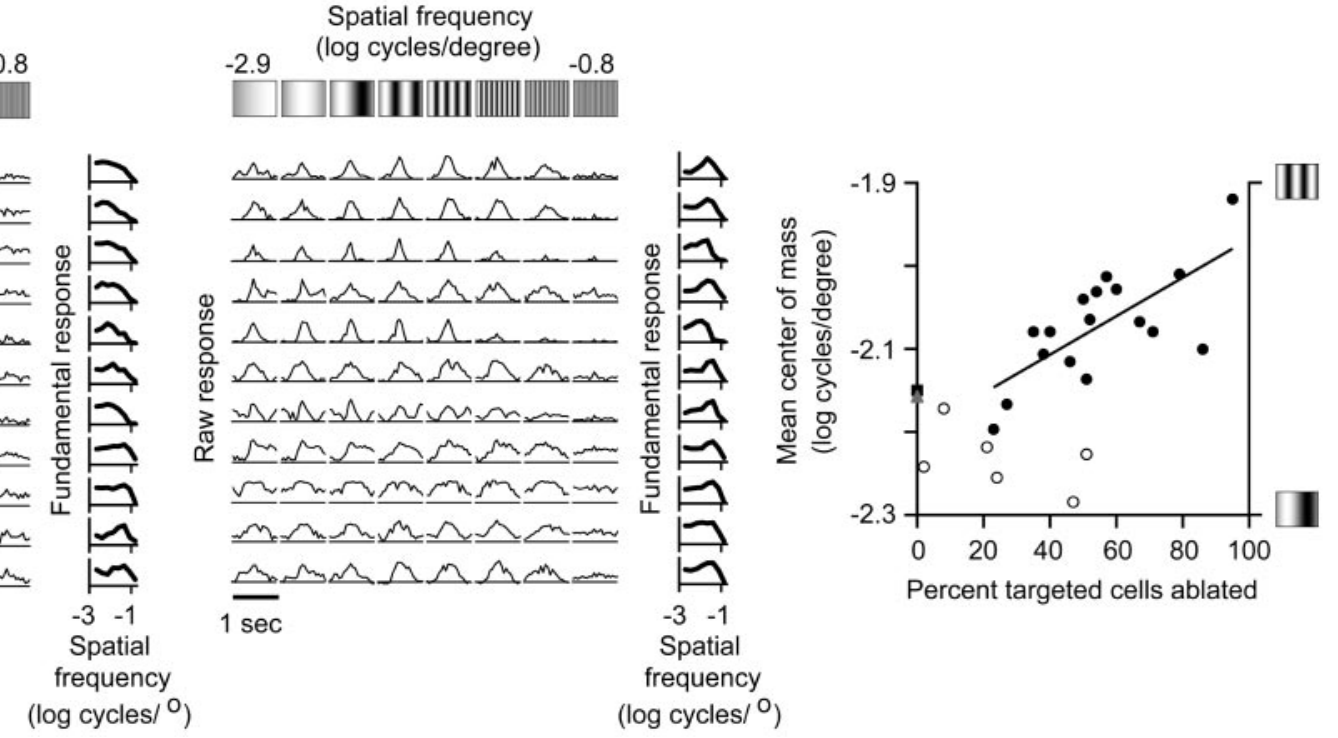

Ablated

B

Figure 3. The spatial tuning curves of ganglion cells from NPY-cell-ablated retinas are shifted away from low spatial frequencies. $A$, Representative ganglion cell responses to drifting sine wave gratings from control and NPY cell-ablated retinas. Responses are normalized to the maximum firing rate. A tuning curve for each cell is shown at the right. $B$, The shift in spatial tuning increases with the degree of ablation ( $p<0.002$, linear regression for ablated retinas; $p<0.001$ for ablated retinas with controls evaluated either as means or separately). The shift is also specific to the NPY cells because ablation of another type of amacrine cell, the V-cells (see Results), did not produce a shift $(p>0.3)$. Each circle indicates a different retina: filled circles indicate NPY cell-ablated retinas; open circles indicate V-cell-ablated retinas; filled triangle indicates the mean of seven nontransgenic controls; gray square indicates the mean of three transgenic controls. The ablated group in $A$ was $>50 \%$ NPY cell-ablated.
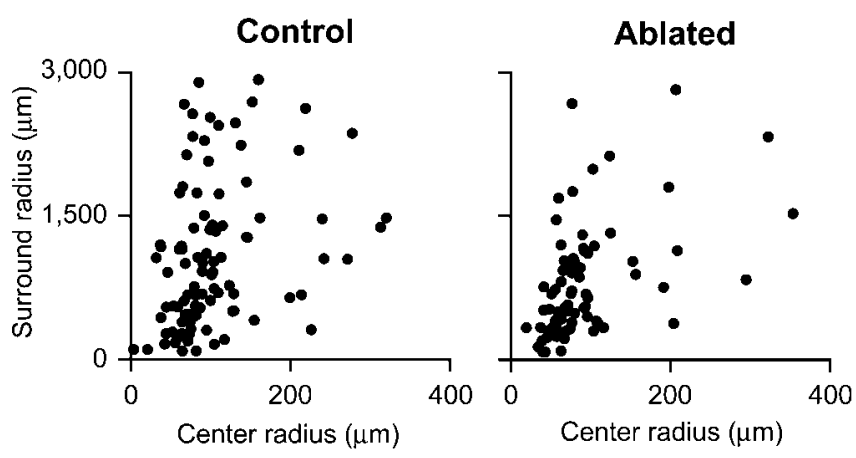

Figure 4. Receptive field surround size is significantly reduced in NPY cell-ablated retinas. Left, Center and surround sizes for all ganglion cells in controls. Right, Center and surround sizes for all ganglion cells in NPY cell-ablated retinas. The mean fraction of cells per retina with center-surround fits was the same for both groups (see Results). All recordings were made near the central retina, within $1.2 \mathrm{~mm}$ from the optic nerve. All ablated retinas were $>50 \% \mathrm{NPY}$ cell-ablated. Note that the large surround sizes observed here are consistent with those reported previously in cat and guinea pig: for cat, mean surround sizes \pm SD were $1633 \pm 851$ $\mu \mathrm{m}$ (for ON cells) and $1863 \pm 667 \mu \mathrm{m}$ (for OFF cells) (Troy et al., 1993); for guinea pig, surround sizes were at least as large as $2500 \mu \mathrm{m}$ because responses were elicited with annuli of that inner diameter (Demb et al., 1999). For our data in mouse, mean surround sizes \pm SD were $1216 \pm 830 \mu \mathrm{m}$ (ON cells) and $967 \pm 666 \mu \mathrm{m}$ (OFF cells).

cells recorded in the central retina (within $1.1 \mathrm{~mm}$ of the optic nerve head) with those from cells recorded in the peripheral retina (within $1 \mathrm{~mm}$ of the peripheral edge). (For cells from the central retina, we used the cells from our control data set described above; for cells from the peripheral retina, we generated a new set of controls. The latter were not included in any analysis besides this eccentricity evaluation.) Our results supported the findings of Sun et al. (2002): we found only a small difference in mean center size, which was not statistically significant, and no difference in mean surround size (mean center size \pm SEM,
Table 1. Receptive field parameter values ${ }^{a}$ (mean \pm SEM) for ganglion cells from controls and NPY-cell ablated retinas

\begin{tabular}{|c|c|c|c|}
\hline & Controls & NPY-cell ablated & $p$ (t test) \\
\hline \multicolumn{4}{|c|}{ Surround size, $\sigma_{\varsigma}(\mu \mathrm{m})$} \\
\hline All cells & $1065 \pm 77$ & $791 \pm 67$ & $<0.05^{*}$ \\
\hline ON cells only & $1177 \pm 121$ & $898 \pm 80$ & $<0.05^{*}$ \\
\hline OFF cells only & $970 \pm 99$ & $554 \pm 114$ & $<0.05^{*}$ \\
\hline \multicolumn{4}{|c|}{ Center size, $\sigma_{c}(\mu \mathrm{m})$} \\
\hline All cells & $104.5 \pm 6.2$ & $91.8 \pm 7.1$ & $>0.4$ \\
\hline ON cells only & $107.5 \pm 7.5$ & $95.8 \pm 9.6$ & $>0.5$ \\
\hline OFF cells only & $102.0 \pm 9.6$ & $83.1 \pm 8.4$ & $>0.2$ \\
\hline \multicolumn{4}{|c|}{ Surround strength, $F_{\mathrm{s}}$} \\
\hline All cells & $4.27 \pm 0.68$ & $3.79 \pm 0.71$ & $>0.5$ \\
\hline ON cells only & $4.17 \pm 1.07$ & $3.53 \pm 0.78$ & $>0.5$ \\
\hline OFF cells only & $4.36 \pm 0.89$ & $4.35 \pm 1.54$ & $>0.5$ \\
\hline \multicolumn{4}{|l|}{ Center strength, $F_{\mathrm{c}}$} \\
\hline All cells & $6.85 \pm 0.62$ & $6.33 \pm 0.52$ & $>0.5$ \\
\hline ON cells only & $7.31 \pm 0.85$ & $5.80 \pm 0.59$ & $>0.2$ \\
\hline OFF cells only & $6.46 \pm 0.90$ & $7.51 \pm 1.02$ & $>0.5$ \\
\hline \multicolumn{4}{|l|}{ Asymmetry, $q$} \\
\hline All cells & $0.24 \pm 0.02$ & $0.22 \pm 0.02$ & $>0.5$ \\
\hline ON cells only & $0.26 \pm 0.03$ & $0.23 \pm 0.03$ & $>0.5$ \\
\hline OFF cells only & $0.22 \pm 0.03$ & $0.18 \pm 0.03$ & $>0.4$ \\
\hline \multicolumn{4}{|l|}{ Phase, $\varphi$ radians } \\
\hline All cells & $1.64 \pm 0.11$ & $1.80 \pm 0.11$ & $>0.4$ \\
\hline ON cells only & $1.66 \pm 0.16$ & $1.76 \pm 0.14$ & $>0.5$ \\
\hline OFF cells only & $1.61 \pm 0.15$ & $1.88 \pm 0.19$ & $>0.4$ \\
\hline Number of cells & 98 & 77 & \\
\hline
\end{tabular}

${ }^{a}$ See Materials and Methods for description of parameters.

* Statistically significant difference between control and NPY cell-ablated groups.

$104 \pm 6 \mu \mathrm{m}$ for cells from the central retina; $n=98$ cells, 9 retinas; vs $131 \pm 15 \mu \mathrm{m}$ for cells the from the peripheral retina; $n=34,4$ retinas; $p=0.05, t$ test; mean surround size, $1065 \pm 77$ $\mu \mathrm{m}$ for cells from the central retina vs $1057 \pm 115 \mu \mathrm{m}$ for cells from the peripheral retina; $p>0.1$ ). 
Second, although there was no observable change in surround size with eccentricity, we nonetheless performed all experiments at approximately the same retinal position, the central retina, with the optic nerve head as a landmark. A requirement for each piece we recorded from was that it included the edge of the optic nerve head. For most retinas, the piece was photographed on the electrode array, so that the distance from the optic nerve head to the furthest electrode could be measured. For experimental retinas, the maximum distance was $1.2 \mathrm{~mm}$; for control retinas, the maximum distance was $1.1 \mathrm{~mm}$, indicating that the two groups were closely matched (range for the experimental group, 0.7-1.2 $\mathrm{mm}$; for controls, $0.8-1.1 \mathrm{~mm}$ ).

Finally, we performed "before-and-after" experiments, in which eccentricity is irrelevant because spatial tuning and receptive field size are measured for each cell before and after ablation treatment. These experiments yielded essentially the same results as the population experiments; spatial tuning curves shifted away from low spatial frequencies, and surrounds became smaller after NPY cell ablation (see below).

Each of these points, the lack of change in surround size with eccentricity in the mouse retina, the sampling from the central retina for both the NPY cell-ablated and control groups, and the fact that the before-and-after experiments yielded the same results as the population studies, provides strong evidence that the observed change in spatial tuning and surround size that accompanied NPY cell ablation cannot be accounted for by an eccentricity confound.

\section{Before-and-after experiments}

In these experiments, we recorded responses from ganglion cells, then ablated the NPY cells, and recorded responses from the same ganglion cells again (Fig. 5). As with the population experiments, two control groups were used: (1) a nontransgenic group that received the identical treatment (the $\beta$-gal substrate, the sensitizing agent, and the ablation illumination); and (2) a transgenic group that received the sensitizing agent and the ablation illumination but no $\beta$-gal substrate.

The results were the following. The tuning curves showed a shift away from low spatial frequencies, a shift that was not observed in controls $(p<0.05, t$ test comparing the mean difference in power at low spatial frequencies between the ablated and controls; $p<0.05, t$ test comparing the mean difference in power at high spatial frequencies between ablated and controls; at low spatial frequencies, there was a loss of power after ablation; at high frequencies, there was a gain of power; see Fig. $5 B$ ). Likewise, there was a significant shrinkage in surround size: the cells with large surrounds had converted into cells with small surrounds, with the shrinkage nearly a factor of $2(p<0.05$, paired $t$ test comparing surround size after ablation with before ablation; Fig. $5 C$ ).

In sum, we performed two sets of experiments on the role of the NPY cells in spatial tuning: population experiments, in which we compared ganglion cell responses from retinas with and without NPY cells; and before-and-after experiments, in which we compared the responses of individual ganglion cells before and after ablation. Both sets converged on the same result: elimination of the NPY cells caused a shift in ganglion cell spatial tuning away from low spatial frequencies, a shift that was caused by a shrinkage of ganglion cell surrounds.

\section{The effect is specific to NPY cells}

The strength of this result lies in the selectivity of the ablation and thus the ability to tie a change in a ganglion cell response property to a specific, biochemically defined type of amacrine cell. Evi-

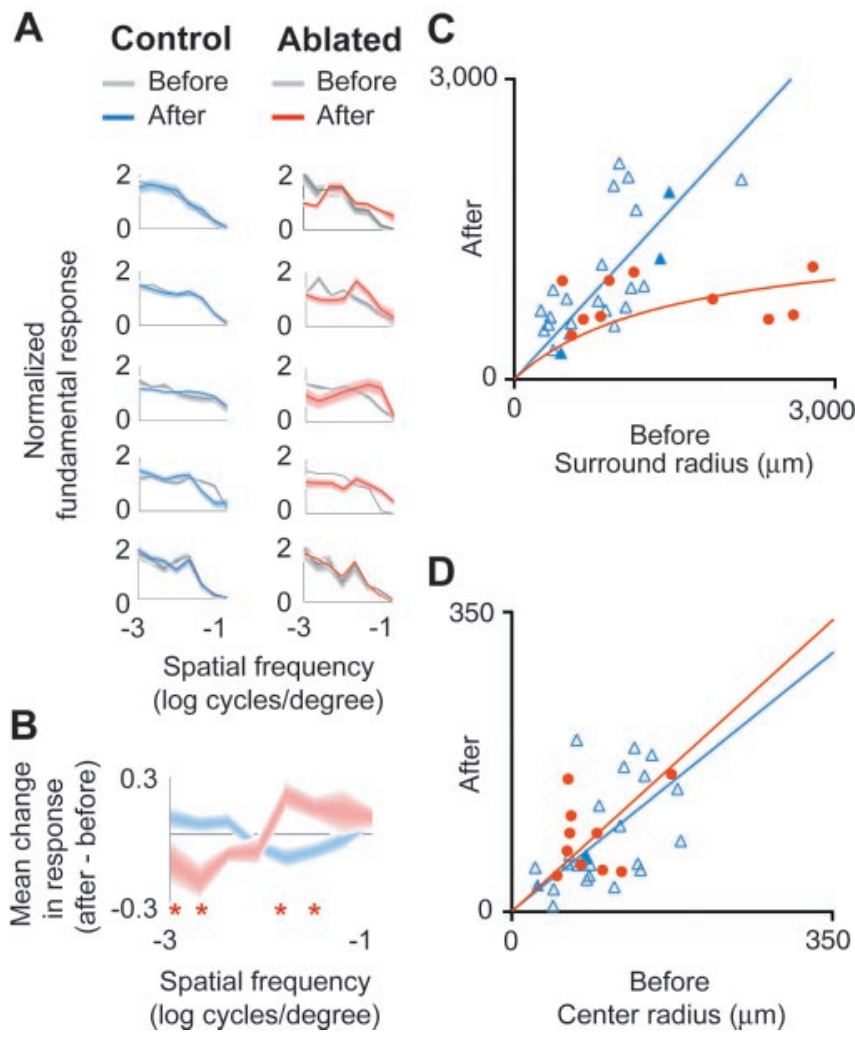

Figure 5. Spatial frequency tuning curves are shifted away from low spatial frequencies, and receptive field surrounds are reduced after NPY cell ablation in before-and-after experiments. $A$, Representative tuning curves before and after NPY cell ablation. Each curve is normalized to the average response; the maximum never exceeded twice the average. SEM is given by line thickness. Left, Tuning curves from controls. Right, Tuning curves from NPY cell-ablated retinas. Gray indicates tuning curve before treatment; color indicates tuning curve after treatment. $B$, Difference in normalized response at each spatial frequency, averaged over cells. SEM is given by line thickness. Blue indicates difference for control group ( $n=26$ cells); red indicates difference for ablated group ( $n=10$ cells). A significant negative shift was observed at low spatial frequencies, and a significant positive shift was observed at high spatial frequencies $\left({ }^{*} p<0.05, t\right.$ test comparing mean differences). C, Surround sizes before and after ablation treatment. Blue triangles indicate surround sizes from controls; red circles indicate surround sizes from NPY cellablated retinas; filled blue triangles are transgenic controls; open blue triangles are nontransgenic controls. (Note that the transgenic controls were internal controls; that is, some retinas were ablated in only one area and thus provided regions that served as internal controls.) The before and after surround sizes from the controls formed a line close to the $45^{\circ}$ line (in fact, slightly higher; slope, 1.15), whereas the before and after surround sizes from the ablated group did not and were better captured by a simple saturating function because the cells with large surrounds fell well below the $45^{\circ}$ line. The function used was $y=x /(1+x / \alpha)$, where $x$ and $y$ are the before and after sizes, respectively, and $\alpha$ was chosen to minimize least squares; as $x \rightarrow$ $\infty, y \rightarrow \alpha=1490 \mu \mathrm{m}$. The top four tuning curves in $A$, under Ablated, correspond to the four cells with the large surrounds in this panel. $D$, Center sizes before and after ablation treatment. The before and after sizes from the NPY-cell ablated retinas and controls both fit lines close to the $45^{\circ}$ line; for neither was the center size significantly different after ablation treatment versus before ( $p>0.1$ for both, paired $t$ test). Symbols are the same as in $C$. The center sizes for the four cells that showed strong surround shrinkage were 75, 93, 99, and 120 . All ablated retinas are $>50 \%$ NPY cell-ablated.

dence for the selectivity is as follows: (1) Previous reports using other $\beta$-gal transgenic lines have shown that the ablation method is selective, as measured by selective uptake of the cell death marker ethidium homodimer into the $\beta$-gal-expressing cells (for examples and quantification, see Nirenberg and Cepko, 1993). Here we verified this for the NPY- $\beta$-gal transgenic line: in two retinas, ethidium uptake was observed in 22 of $23 \beta$-gal expressing cells and only six non- $\beta$-gal-expressing cells ( $n=2$ fields; Fig. $6)$. This amounts to $<2 \%$ nonspecific cell death because each 
A

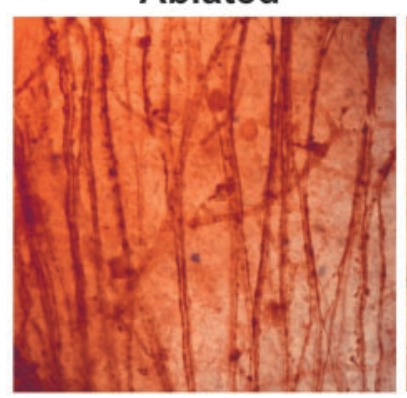

Control

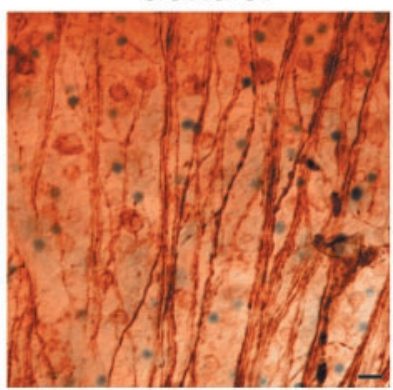

B

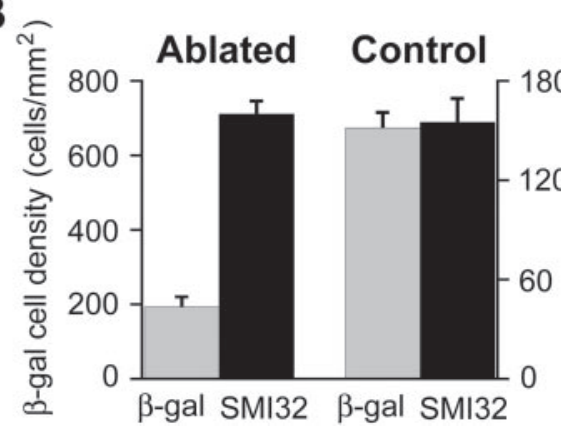

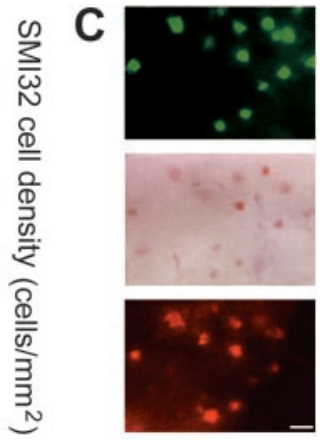

Figure 6. The ablation is selective for the NPY cells. $A, B$, Retinas showing NPY cell ablation did not show concomitant loss of a neighboring population, a population of ganglion cells that lies interspersed with the NPY cells. Left, Retina from the data set shown in Figures 3 and 4, fixed and stained with two markers, one to mark the $\beta$-gal-expressing cells (X-gal; blue) and one to mark the ganglion cells [SMI32 (Nixon et al., 1989), an antibody to a neurofilament protein specific to these ganglion cells; brown]. Right, Control retina from the same data set, fixed and stained with the same two markers. Note that the density of X-gal-stained cells is much less in the ablated retina than in the control, but the density of SMI32-labeled cells remains the same. Scale bar, $20 \mu \mathrm{m}$. $B$, Mean density of X-gal-and SMI32-stained cells in NPY cell-ablated retinas and controls; mean density of SMI32-stained cells is not significantly different (see Results). C, Retinas showing NPY cell ablation did not show nonspecific uptake of ethidium homodimer, a standard cell death marker. Top, Live retina treated with the $\beta$-gal substrate, which labeled the $\beta$-gal-expressing cells with a fluorescent dye. The plane of focus is on the GCL. Middle, Same retina after light activation in the presence of the sensitizing agent (see Materials and Methods). The light activation produces a toxic and light-color product in the cells. Bottom, Same retina after immersion in a solution of ethidium homodimer (for 90 min). Scale bar, $20 \mu \mathrm{m}$. Note that the color product shown in the middle panel is temporary. It fades after fixation and is generally no longer visible in tissue that has been fixed and stained with X-gal, antibodies, and other substances, procedures that take $>1$ or $2 \mathrm{~d}$ (e.g., see Fig. 2C,D).

field examined $(125 \times 250 \mu \mathrm{m}$ in dimension $)$ contained $\sim 250$ cells (Jeon et al., 1998). (2) $\beta$-gal expression was selective for the NPY cells (94\% of cells showing $\beta$-gal expression also showed expression of NPY); thus, $94 \%$ of ablated cells are in fact NPY cells (Fig. 1) (Sinclair and Nirenberg, 2001). (3) Several of the retinas included in the electrophysiological data set were doublestained with a marker for $\beta$-gal and a marker for another cell population to test whether a set of cells interspersed, and often in direct contact, with the $\beta$-gal cells remained present at normal density after ablation. This analysis showed no significant loss in the density of this population (a subtype of ganglion cell) in NPY cell-ablated retinas versus controls $(p>0.8, t$ test comparing mean density of this population in ablated and control retinas: mean density \pm SEM, $150 \pm 9$ cells $/ \mathrm{mm}^{2}$ in NPY cell-ablated retinas and $155 \pm 14$ cells $/ \mathrm{mm}^{2}$ in controls; $n=20$ grids, 4 retinas per group; Fig. 6). (4) The physiological effect observed, the shift in spatial tuning, was associated specifically with the loss of the NPY cells because ablation of another type of amacrine cell, the $\mathrm{V}$-cells, did not produce it (no significant shift was observed; see Fig. 3C). [Ablation of the V-cells has been previously shown to produce a different physiological effect, one on temporal processing (Nirenberg and Meister, 1997).] (5) Ablation of the NPY cells did not produce a host of nonspecific physiological effects. Many other response properties remained intact; i.e., they were not statistically significantly affected, specifically, center size, strength, degree of asymmetry, and surround strength $(p>0.4$ for all these properties, $t$ test comparing them in NPY cell-ablated retinas and controls, shown above). Analysis with other stimuli further supported this: no significant change was observed in the proportion of ON- versus OFF-type cells or in the duration of the $\mathrm{ON}$ and OFF responses when retinas were presented with a flash stimulus ( $p>0.1, t$ test comparing mean fraction of ON or OFF cells and mean response duration in NPY cell-ablated retinas and controls).

\section{The change in spatial tuning is mediated by the primary transmitter of NPY cells rather than NPY}

To determine whether the effects of NPY cells on spatial tuning are mediated by neuropeptide $\mathrm{Y}$ itself, or by the primary neurotransmitter of the NPY cells, we performed spatial tuning analysis on ganglion cells from NPY knock-out mice, that is, mice that have lost the peptide rather than the whole cell. No shift in spatial tuning or surround size was observed ( $p>0.4, t$ test comparing mean center of mass for ganglion cells from NPY cell knock-out mice vs controls; $p>0.5$, $t$ test comparing mean surround size for the two groups; mean center of mass \pm SEM, $-2.13 \pm 0.04 \mathrm{log}$ cycles $/{ }^{\circ}$ for cells from NPY knock-out mice; $n=76$ cells, 3 retinas; $-2.16 \pm 0.03 \log$ cycles $^{\circ}{ }^{\circ}$ for cells from controls; $n=219$ cells, 10 retinas; likewise, mean surround size \pm SEM, $1076 \pm 97$ $\mu \mathrm{m}$ for cells from NPY knock-outs; $n=35$ cells, 3 retinas; $1065 \pm$ $77 \mu \mathrm{m}$ for cells from controls; $n=98$ cells, 10 retinas). These results thus suggest that the effects of NPY cell ablation on spatial tuning are mediated by the primary transmitter of the cells, which is most likely GABA, based on immunostaining with GABA markers (Sinclair and Nirenberg, 2001). However, we cannot rule out the possibility that NPY is involved because it is conceivable that the absence of an effect in the NPY knock-outs is attributable to developmental changes that compensate for the loss of NPY.

\section{Discussion}

This study addresses the question of how the output cells of the retina, the ganglion cells, become tuned to detect spatial patterns on different spatial scales. It is well known that ganglion cells show an array of spatial tuning (Rodieck and Stone, 1965; Enroth-Cugell and Robson, 1966; Shapley and Lennie, 1985). Some cells are tuned to low spatial frequencies, others to high spatial frequencies, and the different tuning allows the cells to extract different information from the visual world (e.g., cells tuned to low spatial frequencies can pull out large objects or contours, whereas cells tuned to high spatial frequencies can pull out fine details; for review, see Marr, 1982; Shapley and Lennie, 1985).

The mechanisms that underlie this spatial tuning have been difficult to disentangle. Broadly speaking, spatial tuning is a function of receptive field organization. Recent studies have suggested that amacrine cells are involved in shaping the spatial receptive field, but the roles of the different amacrine subtypes are not yet clear. Here we examined the role of one subtype, the NPY cells, and found that it is involved specifically in tuning ganglion cells to low spatial frequencies, via a particular modification of the 
receptive field. When the subtype was ablated from the circuitry, ganglion cells tuned to low spatial frequencies underwent a shift toward high spatial frequencies, and the shift was caused by a shrinkage in their receptive field surrounds. The effect was specific to the NPY cells because ablation of another amacrine subtype did not produce it.

These results thus suggest a model for how ganglion cells that are tuned to low spatial frequencies acquire this tuning. The process appears to involve at least two steps. First, a circuit, presumably in the first synaptic layer, sets up a basic center-surround receptive field organization for the ganglion cell, which allows it to detect spatial patterns in general (for review, see Dowling, 1987; Rodieck, 1998); then a second circuit, one involving the NPY cells, adjusts this organization by increasing the size of the surround and, by doing so, extends the tuning of the ganglion cell toward low spatial frequencies. This mode of operation appears to be specific because our results showed that NPY cell ablation did not modify other receptive field properties, such as the size, asymmetry, or strength of the center or the strength of the surround, at least not to a statistically significant extent; rather, it just altered the surround size. The mechanism of action of NPY cells may be to extend the preexisting surround, or it may be to superimpose an additional large surround (for evidence that ganglion cells may have multiple sources of surround inhibition, see Cook and McReynolds, 1998; Flores-Herr et al., 2001).

Is the effect specific to a known mouse ganglion cell class? The effect appears to be specific to cells with large surrounds, but do these constitute a single cell class (e.g., X-cells, Y-cells, ON cells, and OFF cells)? A previous study has reported that mouse ganglion cells do not divide into statistically significantly distinct $\mathrm{X}$ and $Y$ classes, but they do divide into distinct $\mathrm{ON}$ and OFF groups (Carcieri et al., 2003); thus, we focused our analysis on the latter. Our results show that both ON and OFF groups were affected by the NPY cell ablation: in the population experiments, both ON and OFF groups independently showed a decrease in surround size ( $p<0.05$ for both ON and OFF cells, $t$ test comparing mean surround size for each group between control and ablated), and in the before-and-after experiments, the group of 4 cells that showed surround shrinkage included both ON and OFF types (three $\mathrm{ON}$ and one OFF). These findings are consistent with observations, both in our data and those of others, that both $\mathrm{ON}$ and OFF cells include subpopulations with large surrounds (lowspatial frequency tuning). When we compared the distribution of ganglion cells with large surrounds (cells with surround sizes greater than the mean of $1065 \mu \mathrm{m}$ ) with the total distribution of ganglion cells, we found the same proportion of ON and OFF cells: $46 \%$ of cells with large surrounds were ON cells versus $41 \%$ of all ganglion cells, and $43 \%$ of cells with large surrounds were OFF cells versus $44 \%$ of all ganglion cells). Thus, we found no indication that cells with large surrounds, the cells affected by the ablation, constitute just one cell class. Similarly, the large surround cells described in cat by Troy et al. (1993) and in guinea pig by Demb et al. (1999) also include both ON and OFF cells (for data, see Fig. 4 legend).

Consistent with the finding that both ON and OFF cells are affected by the ablation is the fact that the NPY cells form two populations, one with a projection into the ON sublamina of the inner plexiform layer and one with a projection into the OFF sublamina. Thus it is possible that one is responsible for generating the large surrounds of ON ganglion cells, and the other is responsible for the generating the large surrounds of OFF ganglion cells. An alternative possibility is that only one NPY cell population is regulating the surround, and the other is perform- ing another function not picked up readily by our stimulus set. This would suggest a different circuit: in this case, the single population would be affecting the surrounds of both $\mathrm{ON}$ and OFF cells and thus would have to be acting fairly upstream in the circuitry, perhaps through a modulatory pathway. One way to distinguish between these proposals would be to ablate only one population of NPY cells. Focal laser ablation may make this possible.

An additional clue as to how the NPY cells may operate comes from their dendritic tree size. Anatomical analyses of NPY cells in mouse and other species (Hutsler and Chalupa, 1994; Sinclair and Nirenberg, 2001; Oh et al., 2002) show that the spread of their processes is on the scale of a hundred or a few hundred micrometers. This is smaller than the size of the extended surrounds and thus argues that individual NPY cells cannot, by themselves, be generating a large surround. Rather, the NPY cells may be forming a gap junction-coupled population or regulating one because several amacrine cell populations are known to couple (Hampson et al., 1992; Menger and Wässle, 2000; Li et al., 2002; Veruki and Hartveit, 2002).

In summary, the retina contains subpopulations of both ON and OFF ganglion cells that are tuned to low spatial frequencies. These cells are able to evaluate contrast over a large area and may serve either to detect large objects or, more simply, to equalize luminance over large areas. Our results show that these cells acquire this tuning by acquiring a large surround, and the NPY cells are a critical part of this process.

\section{References}

Barlow HB (1953) Summation and inhibition in the frog's retina. J Physiol (Lond) 119:69-88.

Carcieri SM, Jacobs AL, Nirenberg S (2003) Classification of retinal ganglion cells: a statistical approach. J Neurophysiol 90:1704-1713.

Cleland BG, Harding TH, Tulunay-Keesey U (1979) Visual resolution and receptive-field size: examination of two kinds of cat retinal ganglion cell. Science 205:1015-1017.

Cook PB, McReynolds JS (1998) Lateral inhibition in the inner retina is important for spatial tuning of ganglion cells. Nat Neurosci 1:714-719.

Croner LJ, Kaplan E (1995) Receptive fields of P and M ganglion cells across the primate retina. Vision Res 35:7-24.

Demb JB, Haarsma L, Freed MA, Sterling P (1999) Functional circuitry of the retinal ganglion cell's nonlinear receptive field. J Neurosci 19:9756-9767.

Dodd RL (1998) PhD thesis, Stanford University.

Dowling JE (1987) The retina: an approachable part of the brain. Cambridge, UK: Harvard UP.

Enroth-Cugell C, Robson JG (1966) The contrast sensitivity of retinal ganglion cells of the cat. J Physiol (Lond) 187:517-552.

Enroth-Cugell C, Robson JG, Schweitzer-Tong DE, Watson AB (1983) Spatio-temporal interactions in cat retinal ganglion cells showing linear spatial summation. J Physiol (Lond) 341:279-307.

Erickson JC, Clegg KE, Palmiter RD (1996) Sensitivity to leptin and susceptibility to seizures of mice lacking neuropeptide Y. Nature 381:415-421.

Flores-Herr N, Protti DA, Wässle H (2001) Synaptic currents generating the inhibitory surround of ganglion cells in the mammalian retina. J Neurosci 21:4852-4863.

Hampson EC, Vaney DI, Weiler R (1992) Dopaminergic modulation of gap junction permeability between amacrine cells in mammalian retina. J Neurosci 12:4911-4922.

He S, Levick WR (2000) Spatial-temporal response characteristics of the ON-OFF direction selective ganglion cells in rabbit retina. Neurosci Lett 289:2347-2350.

Hutsler JJ, Chalupa LM (1994) Neuropeptide Y immunoreactivity identifies a regularly arrayed group of amacrine cells within the cat retina. J Comp Neurol 346:481-489.

Jeon CJ, Strettoi E, Masland RH (1998) The major cell populations of the mouse retina. J Neurosci 18:8936-8946. 
Kuffler SW (1953) Discharge patterns and functional organization of mammalian retina. J Neurophysiol 16:37-68.

Li W, Zhang J, Massey SC (2002) Coupling pattern of S1 and S2 amacrine cells in the rabbit retina. Vis Neurosci 19:119-131.

Linsenmeier RA, Frishman LJ, Jakiela HG, Enroth-Cugell C (1982) Receptive field properties of $\mathrm{X}$ and $\mathrm{Y}$ cells in the cat retina derived from contrast sensitivity measurements. Vision Res 22:1173-1183.

MacNeil MA, Masland RH (1998) Extreme diversity among amacrine cells: implications for function. Neuron 20:971-982.

MacNeil MA, Heussy JK, Dacheux RF, Raviola E, Masland RH (1999) The shapes and numbers of amacrine cells: matching of photofilled with Golgi-stained cells in the rabbit retina and comparison with other mammalian species. J Comp Neurol 413:305-326.

Mangel SC (1991) Analysis of the horizontal cell contribution to the receptive field surround of ganglion cells in the rabbit retina. J Physiol (Lond) 442:211-234.

Marr D (1982) Vision. San Francisco: Freeman.

Marshak DW (1989) Peptidergic neurons of the macaque monkey retina. Neurosci Res [Suppl] 10:S117-S130.

Masland RH (1988) Amacrine cells. Trends Neurosci 11:405-410.

Menger N, Wässle H (2000) Morphological and physiological properties of the A17 amacrine cell of the rat retina. Vis Neurosci 17:769-780.

Naka KI, Witkovsky P (1972) Dogfish ganglion cell discharge resulting from extrinsic polarization of the horizontal cells. J Physiol (Lond) 223:449-460.

Nirenberg S, Cepko C (1993) Targeted ablation of diverse cell classes in the nervous system in vivo. J Neurosci 13:3238-3251.

Nirenberg S, Meister M (1997) The light response of retinal ganglion cells is truncated by a displaced amacrine circuit. Neuron 18:637-650.

Nirenberg S, Carcieri SM, Jacobs AL, Latham PE (2001) Retinal ganglion cells act largely as independent encoders. Nature 411:698-701.

Nixon RA, Lewis SE, Dahl D, Marotta CA, Drager U (1989) Early posttranslational modifications of the three neurofilament subunits in mouse retinal ganglion cells: neuronal sites and time course in relation to subunit polymerization and axonal transport. Mol Brain Res 5:93-108.

Oh SJ, D’Angelo I, Lee EJ, Chun MH, Brecha NC (2002) Distribution and synaptic connectivity of neuropeptide Y-immunoreactive amacrine cells in rat retina. J Comp Neurol 446:219-234.
Peichl L, Wässle H (1979) Size, scatter, and coverage of ganglion cell receptive field centers in the cat retina. J Physiol (Lond) 291:117-141.

Rodieck RW (1965) Quantitative analysis of cat retinal ganglion cell response to visual stimuli. Vision Res 5:583-601.

Rodieck RW (1998) The first steps in seeing. Sunderland, MA: Sinauer.

Rodieck RW, Stone J (1965) Analysis of receptive fields of cat retinal ganglion cells. J Neurophysiol 28:833-849.

Shapley R, Lennie P (1985) Spatial frequency analysis in the visual system. Annu Rev Neurosci 8:547-583.

Sinclair JR, Nirenberg S (2001) Characterization of Neuropeptide Y-expressing cells in the mouse retina using immunohistochemical and transgenic techniques. J Comp Neurol 432:296-306.

Stone C, Pinto LH (1993) Response properties of ganglion cells in the isolated mouse retina. Vis Neurosci 10:31-39.

Sun W, Li N, HeS (2002) Large-scale morphological survey of mouse retinal ganglion cells. J Comp Neurol 451:115-126.

Taylor WR (1999) TTX attenuates surround inhibition in rabbit retinal ganglion cells. Vis Neurosci 16:285-290.

Thibos LN, Werblin FS (1978) The response properties of the steady antagonistic surround in the mudpuppy retina. J Physiol (Lond) 278:79-99.

Troy JB, Shou T (2002) The receptive fields of cat retinal ganglion cells in physiological and pathological states: where we are after half a century of research. Prog Retin Eye Res 21:263-302.

Troy JB, Oh JK, Enroth-Cugell C (1993) Effect of ambient illumination on he spatial properties of the center and surround of Y-cell receptive fields. Vis Neurosci 10:753-764.

Vaney DI (1990) The mosaic of amacrine cells in the mammalian retina. In: Progress in retinal research (Osborne NN, Chader C, eds), pp 49-100. Oxford: Pergamon.

Veruki ML, Hartveit E (2002) AII (Rod) amacrine cells form a network of electrically coupled interneurons in the mammalian retina. Neuron 33:935-946.

Werblin FS, Dowling JE (1969) Organization of the retina of the mudpuppy, Necturus maculosus. II. Intracellular recording. J Neurophysiol 32:339-355.

Wiesel TN (1960) Receptive fields of ganglion cells in the cat's retina. J Physiol (Lond) 153:583-594. 